
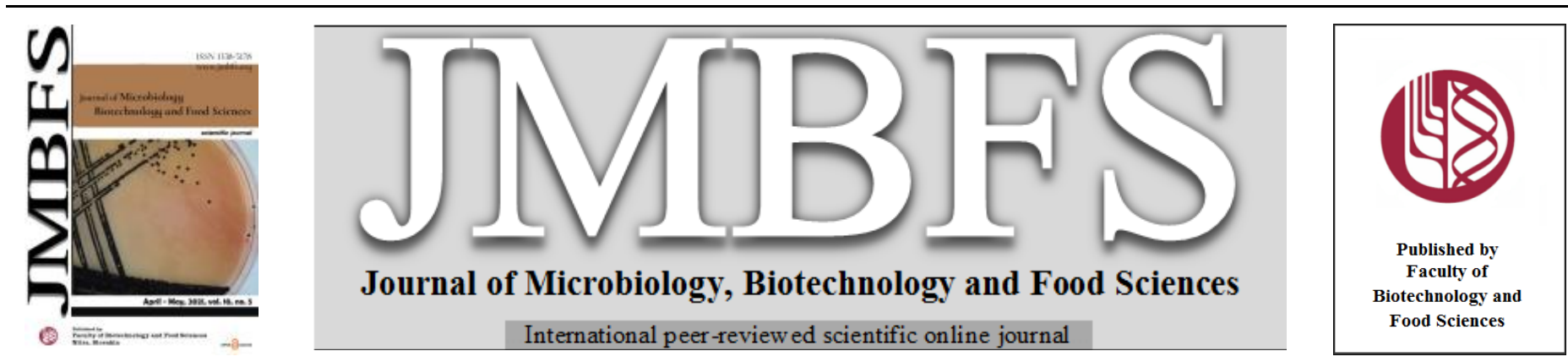

\title{
ASSESSMENT OF CELLULASE COMPLEX SECRETORY CAPACITY OF TRICHODERMA STRAINS AND MORPHOLOGICAL AND MOLECULAR IDENTIFICATION OF THE ISOLATE WITH THE HIGHEST ENZYMATIC SECRETION CAPACITY
}

\section{María Lorena Castrillo ${ }^{1,2 *}$, Gustavo Ángel Bich ${ }^{1,2}$, Natalia Soledad Amerio ${ }^{1,2}$, María Daniela Rodríguez ${ }^{1,2}$, Pedro Dario Zapata ${ }^{1,2}$, Laura Lidia Villalba ${ }^{l}$}

Address(es): Dra. María Lorena CASTRILLO. Misiones National University. Ruta National 12 km 7,5. 3300 (zip code), Posadas, Misiones, Argentina. Tel: (+540376) 4480200 (int. 279)

${ }^{1}$ Laboratorio de Biotecnología Molecular, Instituto de Biotecnología Misiones (InBioMis). Facultad de Ciencias Exactas Químicas y Naturales, Universidad Nacional de Misiones. Posadas, Misiones, Argentina.

${ }^{2}$ CONICET (Consejo Nacional de Investigaciones Científicas y Técnicas).

*Corresponding author: mlc_827@ hotmail.com

https://doi.org/10.15414/jmbfs.1357

\section{ARTICLE INFO}

Received 28. 2. 2019

Revised 25. 11. 2020

Accepted 4. 12. 2020

Published 1. 4. 2021

Regular article OPEN ${ }_{\text {ACCESS }}$

\begin{abstract}
The bioconversion of lignocellulosic biomass into monomeric sugars is a key economic difficulty hindering the profitable use of plant biomass as energy. The production of cellulase is a main factor in the cellulose hydrolysis. Among the main cellulase producers are the filamentous fungi. Therefore, many efforts have been made in obtaining new microorganisms with high cellulase secretion capacity. The cellulase secretory capacity of 28 isolates of Trichoderma was qualitatively and quantitatively evaluated. The detection of cellulolytic fungi was correlated with both Congo red and the dinitrosalicylic acid reagent methods. Based on qualitatively assays, sixteen of the isolates revealed carboxymethyl cellulose degradation ability, where the Trichoderma POS7 isolate showed the highest increase in filter paper activity, endo-1,4- $\beta$-glucanases and $\beta$-glucosidases activities $(\mathrm{p}<0.05)$ in a short incubation time. This isolate was molecularly identified as Trichoderma koningiopsis, based on internal transcribed spacer sequences. Our results provide new information and reveal new microorganism in the hydrolysis of cellulose material. The phylogenetic analysis revealed close positioning of $T$. koningiopsis clade with $T$. viride, $T$. viridescens and $T$. petersenii clades in a closely related group, in concordance with the current taxonomic classification of Trichoderma genus.
\end{abstract}

Keywords: fungal isolate; cellulase activity; morphological characters; ribosomal DNA; Trichoderma koningiopsis

\section{INTRODUCTION}

Our planet is facing an energy crisis as a result of the use of nonrenewable and limited energy resources (Doolotkeldieva and Bobusheva, 2011; Amin and Rahman, 2019). The production of bioenergy from renewable and less costly lignocellulosic materials could bring benefits to the local economy, environment and national energy security (Doolotkeldieva and Bobusheva, 2011; Nigam and Singh, 2011; Akinyele et al., 2014)

Lignocellulosic biomass, a renewable, cheap and abundant resource, has also the advantage that it does not compete with food production (Bandikari et al. 2015). Cellulose is a type of homogeneous polysaccharide that exists in nature as units of cellobiose connected by $\beta$-1,4-glycosidic bonds, and is the most abundant renewable biomass (Zhang et al., 2014). Second-generation biofuels production from lignocellulosic materials includes three main steps: (a) pretreatment, (b) enzymatic hydrolysis of cellulose and hemicellulose to glucose, and (c) ethanol fermentation (Kawai et al., 2013). Hydrolysis of cellulose to glucose requires synergistic action of the cellulase complex (Sadhu et al., 2012), composed of three groups of enzymes: endo-1,4- $\beta$-glucanases (EGs - EC 3.2.1.4) randomly cut $\beta$-1,4-bonds of cellulose chains generating new ends; cellobiohydrolases ( $\mathrm{CBHs}$ EC 3.2.1.91) act in a processive manner on the reducing or nonreducing ends of cellulose polysaccharide chains liberating either cellobiose or soluble cellodextrins as major products; and $\beta$-glucosidases (BGLs - EC 3.2.1.21) hydrolyze soluble cellodextrins and cellobiose to glucose (Zhou et al., 2008; Zhang et al., 2014)

In recent years the interest in cellulase complex has been increased due to many potential applications for these types of enzymes (Rathnan et al., 2013; Adrio and Demain 2014; Patel et al., 2019). In the production of bioethanol, the cost of the enzymes used for hydrolysis needs to be reduced. Also the enzyme's efficiency needs to be modified in order to economically improve the process. The production of cellulase is a main factor in the cellulose hydrolysis (Zhou $\boldsymbol{e}$ al., 2008; Dos Santos Castro et al., 2014). Among the main cellulase producer many filamentous fungi are reported, which can produce an extracellular noncomposite cellulase complex. They are one of the most important sources of commercial cellulase available (Zhang et al., 2014).

Trichoderma genus (Persoon, 1794) comprises an important number of many saprotrophic species with a wide ecological distribution. They are capable of growing on soil, bark, wood, other fungi and inother types of substrates demonstrating their opportunistic potential and their adaptability to different ecological conditions (Druzhinina et al., 2011). Many members in Trichoderma genus are key microorganism in biotechnologically due to their ability to secrete a wide spectrum of enzymes and bioactive compounds (Mandels and Reese, 1957; Doolotkeldieva and Bobusheva 2011; Druzhinina et al., 2011) Therefore, many efforts have been made in obtaining new microorganisms of this genus with high specific cellulase activity and outstanding efficiency (Zhou $\boldsymbol{e} t$ al., 2008). The morphological identification can become difficult and even ambiguous because many fungi are microscopic or have cryptic life cycles (Druzhinina and Kubicek, 2005; Samuels, 2006; Hibbett et al., 2017) Molecular approaches and techniques have been studied and developed to improve fungal identification related to traditional phenotypic methods. The internal transcribed spacer (ITS) region of the ribosomal DNA (rDNA) is one of the most reliable approach to classify a strain at the species level (Leaw $\boldsymbol{e t}$ al., 2006; Hassan et al., 2015; Hibbett et al., 2017).

Nonetheless, in Argentina the studies related to the screening of qualitative and quantitative cellulolytic activities and molecular identification of outstanding biotechnological fungal isolates is scarce.

The objective of this work was to evaluate native Trichoderma fungi with significant cellulase secretion. This work includes: (a) the isolation of new strains of Trichoderma searching for optimal enzyme secretion; (b) the analysis of the cellulase secretion of these strains by means of qualitative and quantitative methods; (c) the evaluation of the congruence between the qualitative and quantitative results; (d) the selection of the Trichoderma isolate with the highest 
cellulase secretion capacity and the morphological and molecular identification of this Trichoderma isolate.

\section{MATERIALS AND METHODS}

\section{Microorganisms}

Twenty-eight Trichoderma isolates were collected from natural ecosystems of Misiones, Argentina. All isolates were identified at genus level by standard macro-micro morphological techniques (Rifai, 1969; Samuels, 2006; Druzhinina et al., 2011; Piontelli, 2015). The isolates were coded as: PROF1, PROF2, PROF3, PROF4, PROF5, PROF6, PROF7, PROF8, NAN9, NAN11, NAN12, NAN13, TEYU14, POS1, POS2, POS3, POS5, POS6, POS7, POS8, POS9, POS10, POS11, TN1, TN2, TN3, TN4 and TN5. The isolates coded as "PROF", "NAN" and "TEYU" were provided by the culture collection of the Universidad Nacional de Misiones. The isolates coded as "POS" and "TN" were isolated from rotten wood samples from non-anthropic environments of Posadas city (Misiones) $\quad\left(27^{\circ} 24^{\prime} 31.8^{\prime \prime} \mathrm{S}, \quad 55^{\circ} 53^{\prime} 48.5^{\prime} \mathrm{W}\right.$; and $27^{\circ} 22^{\prime} 12.2^{\prime}$ 'S $55^{\circ} 57^{\prime} 46.6^{\prime}$ 'W respectively). For the isolation of new native Trichoderma fungi small pieces of rotten wood were placed in potato-dextrose agar plates $3.9 \%$ (w/v) (PDA - Britania SA). After an incubation step for 3 to 5 days at $28 \pm 1^{\circ} \mathrm{C}$ the single fungal colonies were picked using an inoculating rod and inoculated onto a new PDA plate. All the isolates were deposited in the culture collection of the Universidad Nacional de Misiones (Argentina).

\section{Culture conditions}

All the isolates were reactivated in PDA plates for $5-7$ days at $28 \pm 1{ }^{\circ} \mathrm{C}$ under constant photoperiod ( $24 \mathrm{~h}$ light). A white light tube $(6500 \mathrm{~K}, 18 \mathrm{w})$ was used as supplementary light with alight/dark periodregulated with a Zurich XTIM03205 digital timer.

To prepare the fungal inocula for qualitative assays, $5 \mathrm{~mm}$-agar plugs from each fungal isolate grown in PDA were cut and transferred to agar plates containing solid Mandels' medium (Mandels and Reese, 1957) with the following modifications: $1.7 \%(\mathrm{w} / \mathrm{v})$ agar-agar and $0.5 \%(\mathrm{w} / \mathrm{v})$ sodium carboxymethy cellulose (CMC) as only carbon source. The agar plates were incubated for 5 days at $28 \pm 1{ }^{\circ} \mathrm{C}$ under constant photoperiod ( $24 \mathrm{~h}$ light).

To prepare the fungal inocula for quantitative assays, spore suspensions with 10 spores/mL concentration were used as initial inoculum for each experiment and transferred to $250 \mathrm{~mL}$-Erlenmeyer flasks containing $50 \mathrm{~mL}$ of liquid Mandels medium with $0.5 \%(w / v) ~ C M C$ as only carbon source. The Erlenmeyer flasks were incubated under static conditions for 5 days at $28 \pm 1{ }^{\circ} \mathrm{C}$ under constan photoperiod (24 h light $)^{8}$. Daily aliquots of $1.5 \mathrm{~mL}$ of supernatant were taken and used as crude enzyme extract to assay extracellular cellulase secretion in quantitative screening assays.

\section{Biochemical analyses}

Qualitative cellulase activities screening assays of Trichoderma isolates

The qualitative cellulase activity of fungal isolates was determined based on their ability to grow and form clear zones around colonies on solid Mandels' medium (Mandels and Reese, 1957). The surface of the plates with medium and grown fungal colonies was flooded with $0.1 \%(\mathrm{w} / \mathrm{v})$ Congo red solution (BioPack SA) and incubated for $15 \mathrm{~min}$ at room temperature. The dye was removed with sterile distilled water followed by incubation for 10 more minutes at room temperature The plates were further treated by flooding with $1 \mathrm{M} \mathrm{NaCl}$ solution for $5 \mathrm{~min}$. The ratio of the diameter of the clear zone to the diameter of the colony growth was measured (Ouyang et al., 2006; Doolotkeldieva and Bobusheva 2011). The cellulase activity of each Trichoderma isolate was determined using a qualitative scale, where the number of + represents qualitative enzymatic activity, ranging from null (-) to maximum (++++) enzymatic activity.

\section{Quantitative cellulase activities screening assays of Trichoderma isolates}

The quantitative cellulase activity of the fungal isolates was determined by their EGs, CBHs and BGLs activities. The synergic effect of the cellulase complex was determined by filter paper activity (FPA). These activities were performed as reported previously (Rodriguez et al., 2019). The FPA and EGs activities were determined according to the International Union of Pure and Applied Chemistry tests (Ghose, 1987). FPA and EGs were assayed by measuring the release of reducing sugars. FPA activity was assessed in a reaction mixture containing 0.1 $\mathrm{mL}$ of crude enzyme, $10 \mathrm{mg}$ of Whatman No. 1 filter paper as substrate and 0.2 $\mathrm{mL}$ of $50 \mathrm{mM}$ sodium acetate buffer $(\mathrm{pH} 4.8)$ incubated at $50^{\circ} \mathrm{C}$ for $60 \mathrm{~min}$. EGs activity was assessed in a reaction mixture containing $0.1 \mathrm{~mL}$ of crude enzyme and $0.1 \mathrm{~mL}$ of $2 \%(\mathrm{w} / \mathrm{v})$ of CMC solution in $50 \mathrm{mM}$ sodium acetate buffer $(\mathrm{pH}$ 4.8) incubated at $50^{\circ} \mathrm{C}$ for $30 \mathrm{~min}$. The $\mathrm{CBHs}$ activity was assessed according to Wood and Bhat (1988). CBHs activity was assessed by measuring the release of reducing sugars in a reaction mixture containing $0.1 \mathrm{~mL}$ of crude enzyme and 0.1 $\mathrm{mL}$ of $1 \%(\mathrm{w} / \mathrm{v})$ of cellulose in $50 \mathrm{mM}$ sodium acetate buffer $(\mathrm{pH} 4.8)$ incubated at $50^{\circ} \mathrm{C}$ for $60 \mathrm{~min}$ and $125 \mathrm{rpm}$. Reducing sugars were assayed by dinitrosalicyclic acid method (Miller, 1959). One unit of FPA, EGs or CBHs activity was defined as the amount of enzyme required to liberate $1 \mu \mathrm{mol}$ of glucose per minute from each substrate under the assay conditions (Rodriguez $\boldsymbol{e t}$ al., 2019).

The BGLs activity was assessed using p-nitrophenyl- $\beta$-D-glucopyranoside method (Bailey, 1981). The release of p-nitrophenol was measured at $400 \mathrm{~nm}$ from a reaction mixture containing $0.9 \mathrm{~mL}$ of $0.03 \mathrm{M}$ p-nitrophenyl glucopyranoside in $50 \mathrm{mM}$ acetate buffer $(\mathrm{pH} 4.8)$ and $0.1 \mathrm{~mL}$ of suitably diluted enzyme, incubated at $50^{\circ} \mathrm{C}$ for $15 \mathrm{~min}$ and $125 \mathrm{rpm}$. One unit of BGLs activity was defined as the amount of enzyme required to liberate $1 \mu \mathrm{mol}$ of $\mathrm{p}$ nitrophenol per minute under the assay conditions (Rodriguez et al., 2019).

\section{Congruence between qualitative and quantitative screening assays}

To compare the congruence between qualitative and quantitative screening assays, the isolates classified as positives $(++,+++$ and ++++$)$ and two isolates with low (+, PROF2 isolate) and null (-, NAN9 isolate) activities were selected and statistically compared among them. In all cases, the enzymatic activities (EGs - CBHs - BGLs - FPA) were measured by the methods previously mentioned and the isolate with the highest cellulase activities was selected (Sazci et al., 1986; Florencio et al., 2012).

\section{Data Analysis}

All experiments were conducted in triplicate. The experimental runs were designed, and the results were analyzed using the Statgraphic Centurion program (StatPoint, Inc., version 15.2.05) and GraphPad Prism version 6.0 for Windows (GraphPad Software, San Diego, CA, USA). Analysis of variance (ANOVA) was used for all data analysis. The Least Significant Difference (LSD) test was selected and used to establish differences among levels of a factor. A confidence level of $95 \%$ was applied. The results of quantitative assays represent the mean values \pm the standard deviation of the mean (SD)

\section{Morphological identification}

The Trichoderma POS7 isolate with the highest cellulase secretion capacity was reactivated in PDA plates and incubated for 3 days at $28 \pm 1{ }^{\circ} \mathrm{C}$ in a $12 \mathrm{~h}$ light/12 $\mathrm{h}$ dark photoperiod. After the incubation period, the macroscopic and microscopic features of the selected isolate were described. The macroscopic features observed of the fungal colony were: growth rate, morphology and surface and reverse color in PDA and malt extract agar (MEA- Britania SA) culture media. The records of the colony diameter, shape, arrangement, color and texture were documented at 24, 48 and 72 hours using the ImageJ 1.4 program (Schneider et al., 2012).

For the microscopic identification the microculture technique and lactophenol cotton blue staining with the adhesive tape method were used to facilitate the observation of structural features like conidiophores and sizes, branching pattern, shape and arrangement of conidia, pigmentation, among others (Samson et al., 1988; Kubicek and Harman, 2002; Prats, 2007; Piontelli, 2015). For light microscopic observations the preparations were made from the edge of the growing colony. A Carl Zeiss - West Germany model 467065-9902-18VA ligh microscope was used. Examinations were made with the oil immersion augmentation to establish details of conidial shape and ornamentation. The mean values and standard deviation of at least 10 measured structures were calculated and indicated to determine the microscopic measurements of the reproductive structures.

\section{Molecular identification and phylogenetic analysis}

For DNA extraction mycelia of the Trichoderma POS7 isolate were grown in malt extract broth $1.27 \%$ (w/v) (ME - Britania SA) at $28 \pm 1{ }^{\circ} \mathrm{C}$ for 5 days in the dark. The extraction of genomic DNA was performed as reported previously (Castrillo et al., 2012; Bich et al., 2017). DNA was resuspended in $30 \mu \mathrm{L}$ of sterile distilled free of DNAse water (Biopak®). DNA extracted was further examined by electrophoresis in $1 \%(\mathrm{w} / \mathrm{v})$ agarose gels (InBio) and stained with Gel Red Solution (Biotium, 10,000 X). The DNA purity was determined by the A 260 /A 280 ratio (Sambrook et al., 1989; Castrillo et al., 2016).

For the analysis of this section the ITS1-5.8S-ITS2 region was evaluated. PCR amplifications were carried out in a $20 \mu \mathrm{L}$ reaction mixture which included $1 \mathrm{X}$ PCR Buffer, $2.5 \mathrm{mM} \mathrm{MgCl} 2,200 \mu \mathrm{M}$ of dNTP mix, 10 pmol of each of the amplification primers, $0.5 \mathrm{u}$ of Taq polymerase (InBio), and $1 \mu \mathrm{g}$ of genomic DNA (Castrillo et al., 2012; Bich et al., 2017). The primers used were the ITS1 F- (5'-TCCgTAggTgAACCTgCgg-3') and ITS4 R- (5'TCCTCCgCTTATTgATATgC-3') (White et al., 1990). The amplification protocol consisted of an initial denaturation at $94^{\circ} \mathrm{C}$ for $4 \mathrm{~min}$, followed by 35 PCR amplification cycles of $94^{\circ} \mathrm{C}$ for $40 \mathrm{~s}, 53^{\circ} \mathrm{C}$ for $40 \mathrm{~s}$ and $72^{\circ} \mathrm{C}$ for $40 \mathrm{~s}$. A final extension step of $72^{\circ} \mathrm{C}$ for 10 min was included (Bich et al., 2017). The amplified fragment was examined by electrophoresis in $2 \%(\mathrm{w} / \mathrm{v})$ agarose gels (InBio) and stained with Gel Red Solution (Biotium, 10,000 X). Both strands of 
PCR products were sequenced by Macrogen Korea for further phylogenetic studies.

The ITS1-5.8S-ITS2 nucleotide sequence of the Trichoderma POS7 isolate was compared with deposited sequences in GenBank, Fungal barcoding and TrichOKEY databases for species identification. Sixty-nine ITS1-5.8S-ITS2 sequences were selected and retrieved from GenBank and Fungal barcoding databases representing species within the Trichoderma genus (Table 1). Nucleotide sequences retrieved in this study consisted of about $600 \mathrm{bp}$ which correspond to the ITS1-5.8S-ITS2 and partial 18S and 28S regions (Castrillo $\boldsymbol{e}$ al., 2016). A sequence of Hypomyces subiculosus (EU280093) was used as an outgroup to root the Trichoderma phylogenetic tree. DNA sequences were aligned using the Clustal W program (Thompson et al., 1994). The analyses were based on a distance-based method (Neighbor joining, NJ) and two phylogenetic methods (Maximum Likelihood, ML and Maximum Parsimony, MP). Support for specific clades represented in the tree was estimated by bootstrap analysis of 1,000 replicates. Nucleotide divergences were estimated using Kimura's two-parameter method. The MEGA 6.0 package (Tamura et al. 2013) was used for the analyses. Phylogenetic data have been submitted to $\begin{array}{llll}\text { TreeBase with } & \text { submission } 2003\end{array}$ (http://purl.org/phylo/treebase/phylows/study/TB2:S22003).

Table 1 Genbank accession numbers retrieved from databases.

\begin{tabular}{|c|c|c|c|c|}
\hline Species & $\begin{array}{l}\text { Strain } \\
\text { number }\end{array}$ & $\begin{array}{l}\text { Isolation } \\
\text { source }\end{array}$ & Country & $\begin{array}{c}\text { ITS rDNA } \\
\text { accession } \\
\text { number }\end{array}$ \\
\hline T. asperellum & GXNN1001 & - & China & JQ040311 \\
\hline T. asperellum & $\begin{array}{l}\text { DAOM } \\
233975\end{array}$ & - & Perú & EU280132 \\
\hline $\begin{array}{l}T . \\
\text { brevicompactum }\end{array}$ & PROF 1 & Soil & Argentina & JX069193 \\
\hline $\begin{array}{l}T . \\
\text { brevicompactum }\end{array}$ & CIB T37 & - & Colombia & EU280087 \\
\hline $\begin{array}{l}T . \\
\text { brevicompactum }\end{array}$ & $\begin{array}{l}\text { SVPRT- } \\
\text { TBC01 }\end{array}$ & Soil & India & JX908732 \\
\hline $\begin{array}{l}T . \\
\text { brevicompactum }\end{array}$ & CEN522 & $\begin{array}{l}\text { Soil of guava } \\
\text { crop }\end{array}$ & Brazil & КС561076 \\
\hline $\begin{array}{l}T . \\
\text { brevicompactum }\end{array}$ & $\mathrm{T}-28$ & Soil & - & KC884785 \\
\hline T. ceramicum & GJS 88-70 & $\begin{array}{l}\text { Decorticated } \\
\text { wood }\end{array}$ & USA & AY737764 \\
\hline T. ceramicum & $\begin{array}{l}\text { CBS } \\
114576\end{array}$ & - & USA & FJ860743 \\
\hline T. chlorosporum & $\mathrm{PC} 4$ & - & - & AF275322 \\
\hline T. chlorosporum & GJS 98-1 & $\log$ & $\begin{array}{l}\text { Costa } \\
\text { Rica }\end{array}$ & AY737762 \\
\hline T. citrinoviride & EGE-K-128 & Timber & Turkey & JX125615 \\
\hline T. citrinoviride & T196 & - & - & HQ596981 \\
\hline T. citrinoviride & Tc-03 & - & India & KF294838 \\
\hline T. citrinoviride & $\begin{array}{l}\text { NBAII Tv- } \\
5\end{array}$ & $\begin{array}{c}\text { Cotton } \\
\text { rhizosphere }\end{array}$ & India & JQ013145 \\
\hline T. citrinoviride & TN5 native & $\begin{array}{l}\text { Decaying } \\
\text { wood }\end{array}$ & Argentina & KT030886 \\
\hline T. citrinoviride & KUC1274 & Bamboo & $\begin{array}{l}\text { South } \\
\text { Korea }\end{array}$ & НМ008920 \\
\hline T. citrinoviride & KUC5160 & - & - & HM534655 \\
\hline T. crassum & $\begin{array}{l}\text { DAOM } \\
164916\end{array}$ & - & Canada & EU280067 \\
\hline T. crassum & $\begin{array}{l}\text { DAOM } \\
233775\end{array}$ & - & Guatemala & EU280084 \\
\hline T. estonicum & GJS 96-129 & $\begin{array}{l}\text { Hymenochaete } \\
\text { tabacina }\end{array}$ & Estonia & AY737767 \\
\hline T. estonicum & $\begin{array}{l}\text { CBS } \\
111147\end{array}$ & 10 & - & FJ860752 \\
\hline T. hamatum & $\begin{array}{l}\text { DAOM } \\
237553\end{array}$ & - & Peru & EU280136 \\
\hline T. hamatum & CiB T144 & - & Colombia & EU280105 \\
\hline T. harzianum & $\begin{array}{l}\text { PROF2 } \\
\text { native }\end{array}$ & Soil & Argentina & JX069196 \\
\hline T. harzianum & $\begin{array}{l}\text { PROF6 } \\
\text { native }\end{array}$ & Soil & Argentina & JX069198 \\
\hline T. harzianum & $\begin{array}{l}\text { TEYU14 } \\
\text { native }\end{array}$ & Soil & Argentina & JX069201 \\
\hline T. harzianum & $\begin{array}{l}\text { NAN13 } \\
\text { native }\end{array}$ & Soil & Argentina & JX069200 \\
\hline T. harzianum & $\begin{array}{l}\text { POS3 } \\
\text { native }\end{array}$ & $\begin{array}{l}\text { Decaying } \\
\text { wood }\end{array}$ & Argentina & KT030877 \\
\hline T. harzianum & $\begin{array}{l}\text { PROF3 } \\
\text { native }\end{array}$ & Soil & Argentina & JX069197 \\
\hline T. harzianum & PROF7 & Soil & Argentina & JX069199 \\
\hline
\end{tabular}

\begin{tabular}{|c|c|c|c|c|}
\hline T. harzianum & $\begin{array}{l}\text { native } \\
\text { SZMC } \\
20869\end{array}$ & Soil & Hungary & JX173873 \\
\hline T. harzianum & OTU680 & - & - & GU934533 \\
\hline T. koningiopsis & $\mathrm{T}-51$ & Soil & - & KC884808 \\
\hline T. koningiopsis & $\mathrm{T}-16$ & Soil & - & KC884773 \\
\hline T. koningiopsis & $\mathrm{T}-54$ & Soil & - & KC884811 \\
\hline T. koningiopsis & $\mathrm{T}-57$ & Soil & - & KC884814 \\
\hline T. koningiopsis & DMC 795b & - & - & EU718083 \\
\hline T. koningiopsis & CiB T01 & - & Colombia & EU280108 \\
\hline T. koningiopsis & $\mathrm{T}-1$ & Soil & - & KC884758 \\
\hline T. koningiopsis & Dis3264 & $\begin{array}{l}\text { Theobroma } \\
\text { gileri }\end{array}$ & Ecuador & DQ379015 \\
\hline T. koningiopsis & Tri021 & - & - & HQ229944 \\
\hline T. koningiopsis & CQSQ1002 & - & China & JQ040365 \\
\hline T. koningiopsis & $\begin{array}{l}\text { DAOM } \\
229982\end{array}$ & - & Peru & EU280142 \\
\hline T. koningiopsis & $\begin{array}{l}\text { DAOM } \\
233971\end{array}$ & - & Peru & EU280131 \\
\hline $\begin{array}{l}T . \\
\text { longibrachiatum }\end{array}$ & PRT-TL10 & Soil & - & KC582841 \\
\hline $\begin{array}{l}T . \\
\text { longibrachiatum }\end{array}$ & $\mathrm{T} 50$ & - & China & FJ459964 \\
\hline $\begin{array}{l}T . \\
\text { longibrachiatum }\end{array}$ & IHB F 539 & $\begin{array}{c}\text { Tea } \\
\text { rhizosphere }\end{array}$ & - & HM461859 \\
\hline $\begin{array}{l}T . \\
\text { longibrachiatum }\end{array}$ & TNAU-TL1 & - & - & DQ200259 \\
\hline $\begin{array}{l}T . \\
\text { longibrachiatum }\end{array}$ & $\begin{array}{l}\text { POS5 } \\
\text { native }\end{array}$ & $\begin{array}{l}\text { Decaying } \\
\text { wood }\end{array}$ & Argentina & KT030878 \\
\hline $\begin{array}{l}T . \\
\text { longibrachiatum }\end{array}$ & CIB T29 & - & Colombia & EU280095 \\
\hline T. petersenii & GJS 04-351 & Wood & USA & DQ323440 \\
\hline T. petersenii & GJS 04-355 & - & USA & DQ323441 \\
\hline T. pulvinatum & $\begin{array}{l}\text { NBRC } \\
9385\end{array}$ & - & Japan & JN943376 \\
\hline T. pulvinatum & $\begin{array}{l}\text { NBRC } \\
8543\end{array}$ & - & Japan & JN943375 \\
\hline T. pulvinatum & $\begin{array}{l}\text { NBRC } \\
8544\end{array}$ & - & Japan & JN943374 \\
\hline T. reesei & A1S3-D22 & Beach soil & - & KJ767092 \\
\hline T. reesei & RSPG_24 & Soil & Thailand: & $\mathrm{KC} 478546$ \\
\hline T. sinensis & JZ-129 & Soil & China & HQ637329 \\
\hline T. sinensis & $\begin{array}{l}\text { DAOM } \\
230004\end{array}$ & Bark & Taiwan & HQ260623 \\
\hline T. virens & $\begin{array}{l}\text { DAOM } \\
233974\end{array}$ & - & Peru & EU280090 \\
\hline T. virens & TR039 & $\begin{array}{c}\text { Trachymyrmex } \\
\text { septentrionalis } \\
\text { nest }\end{array}$ & USA & HQ608079 \\
\hline T. viride & $\begin{array}{l}\text { ATCC } \\
28038\end{array}$ & Soil & USA & AY380909 \\
\hline T. viride & GJS 90-95 & $\begin{array}{l}\text { Decorticaded } \\
\text { wood }\end{array}$ & USA & DQ315455 \\
\hline T. viride & $\operatorname{Tr} 21$ & Soil & USA & AJ230675 \\
\hline T. viridescens & $\begin{array}{l}\text { DAOM } \\
237554\end{array}$ & - & Peru & EU280135 \\
\hline T. viridescens & $\begin{array}{l}\text { DAOM } \\
234234\end{array}$ & - & Guatemala & EU280119 \\
\hline T. viridescens & $\begin{array}{l}\text { DAOM } \\
233967\end{array}$ & - & Peru & EU280137 \\
\hline T. viridescens & CiB T10 & - & Colombia & EU280104 \\
\hline
\end{tabular}

\section{RESULTS}

\section{Biochemical analyses}

Qualitative cellulase activities screening assays of Trichoderma isolates Six isolates, PROF5, PROF7, NAN13, TEYU14, POS3 and POS7, showed the highest qualitative enzymatic activity, and therefore were classified as ++++ Then the PROF1, PROF4, PROF6, PROF8, POS6, POS11 and TRICHO4 isolates were classified as +++, and POS8, POS10 and NAN11 isolates were classified as ++. All these isolates were classified as effective in the qualitative enzyme secretion. The isolates that showed low enzymatic activity were PROF2, PROF3, POS1, POS5, POS9, NAN12, TRICHO1 and TRICHO2, and as a consequence were classified as + , followed by NAN9, TRICHO3, TRICHO5 and POS2 isolates that showed null qualitative enzymatic activity, which were classified as - (Fig 1). 

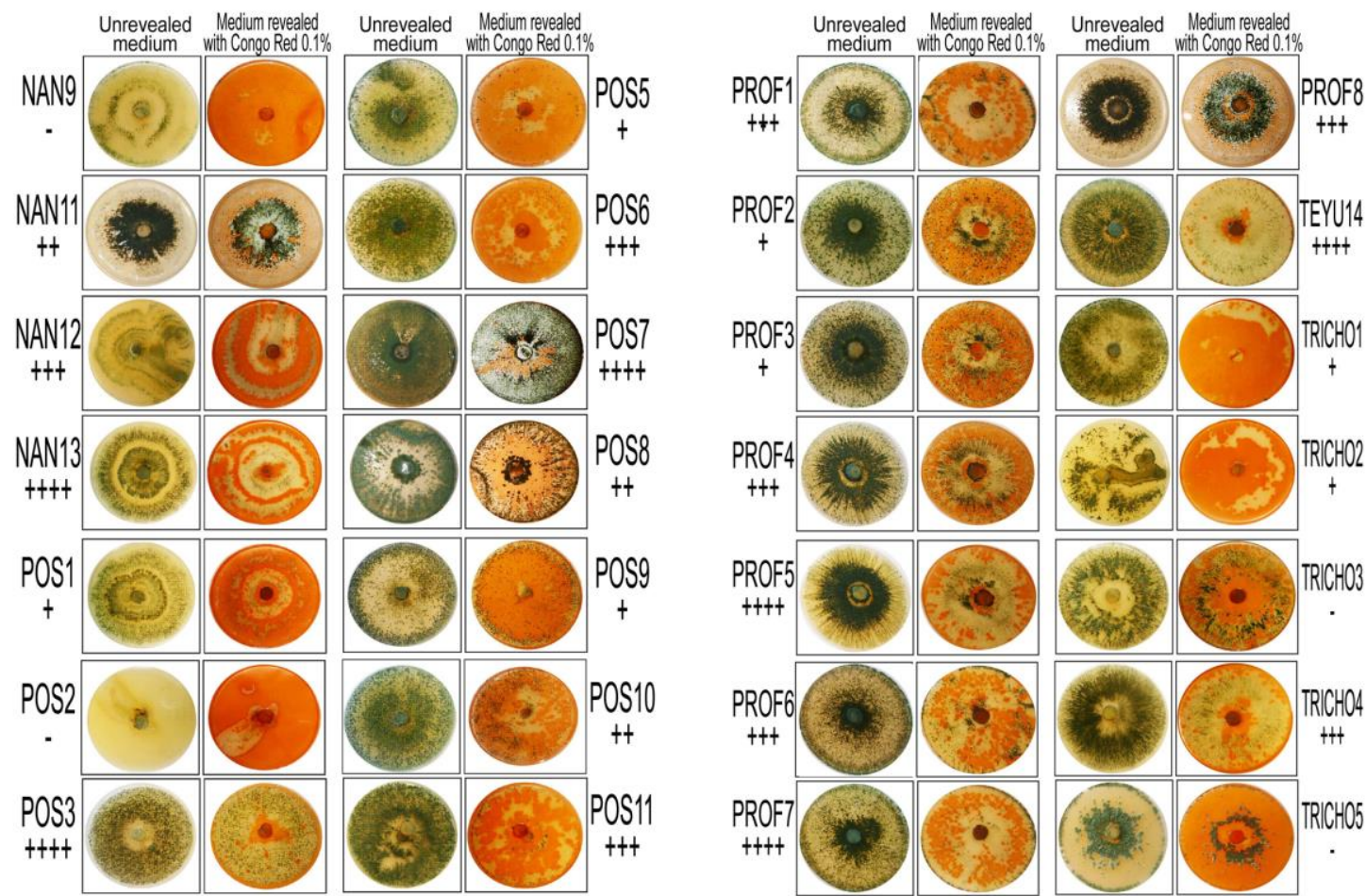

Figure 1 Qualitative enzymatic activity of the twenty-eight isolates of Trichoderma on solid Mandels' medium detected by Congo red method. Number of crosses (+ to ++++) indicates positive reaction intensity (weak to very strong); (-) indicates qualitative no detectable reaction.

Quantitative cellulase activities screening assays of Trichoderma isolates

The isolates classified previously as effective in the qualitative enzyme secretion $(++++,+++$ and ++$)$, were selected to assess the quantitative cellulase activity. Most of the isolates revealed ability to CMC degradation, where the Trichoderma POS7 isolate showed the highest increase in FPA, EGs and BGLs activities ( $\mathrm{p}<0.05)$. Regarding CBHs activity, the highest activity increase was observed in PROF7, PROF4 and POS7 isolates $(\mathrm{p}<0.05)$. Furthermore, in most cases the Trichoderma POS7 isolate showed the highest enzymatic activities in the shortest incubation time (Table 2). The Trichoderma POS7 isolate, based on the qualitative and quantitative cellulase activities assayed, was selected as a biotechnological isolate with outstanding enzymatic activity.
Congruence between qualitative and quantitative screening assays

It was clearly possible to verify a statistical congruence between the fast qualitative and the precise quantitative assays. All the isolates classified as ++++ had greater quantitative activities than the isolates classified as +++ and subsequently than the isolates classified as ++. Also, the PROF2 isolate with low qualitative activity showed greater quantitative activities than the NAN9 isolate with null qualitative activity $(\mathrm{p}<0.05)$, corresponding to the two isolates with the smallest quantitative activities (Table 2)

Table 2 Quantitative cellulase activities screening assays of 18 Trichoderma isolates from Misiones, Argentina.

\begin{tabular}{|c|c|c|c|c|c|c|}
\hline \multirow{3}{*}{$\begin{array}{l}\text { Fungal } \\
\text { isolate }\end{array}$} & \multicolumn{6}{|c|}{ Quantitative assays $(\mathrm{U} / \mathrm{L})(\text { mean } \pm \mathrm{SD})^{1}$} \\
\hline & \multicolumn{3}{|c|}{ FPA activity } & \multicolumn{3}{|c|}{ EGs activity } \\
\hline & Day 3 & Day 4 & Day 5 & Day 3 & Day 4 & Day 5 \\
\hline PROF5 & $30.1 \pm 2.8^{\mathrm{c}}$ & $23.7 \pm 0.5^{\mathrm{d}, \mathrm{e}}$ & $27.5 \pm 0.8^{\mathrm{c}, \mathrm{d}}$ & $94.1 \pm 4.6^{\mathrm{c}, \mathrm{d}}$ & $104.4 \pm 3.2^{\mathrm{c}}$ & $120.8 \pm 9.2^{b}$ \\
\hline PROF7 & $30.9 \pm 2.6^{\mathrm{c}}$ & $26.1 \pm 1.8^{\mathrm{c}, \mathrm{d}}$ & $35.3 \pm 0.7^{\mathrm{b}}$ & $79.6 \pm 1.6^{\mathrm{d}, \mathrm{e}}$ & $85.9 \pm 6.9^{\mathrm{d}}$ & $70.2 \pm 0.9^{f}$ \\
\hline NAN13 & $26.6 \pm 1.5^{\mathrm{c}, \mathrm{d}}$ & $34.2 \pm 4.6^{\mathrm{b}, \mathrm{c}}$ & $24.8 \pm 2.6^{\mathrm{c}, \mathrm{d}}$ & $74.2 \pm 1.6^{\mathrm{e}, \mathrm{f}}$ & $81.5 \pm 4.9^{\mathrm{d}, \mathrm{e}}$ & $100.4 \pm 7.1^{\mathrm{c}}$ \\
\hline TEYU14 & $33.2 \pm 1.7^{\mathrm{c}}$ & $35.9 \pm 2.3^{\mathrm{b}}$ & $29.7 \pm 4.1^{\mathrm{c}, \mathrm{d}}$ & $89.8 \pm 1.9^{\mathrm{d}}$ & $99.4 \pm 3.7^{\mathrm{c}}$ & $130 \pm 7.2^{\mathrm{a}, \mathrm{b}}$ \\
\hline POS3 & $25.5 \pm 0.9^{\mathrm{c}, \mathrm{d}}$ & $21.9 \pm 0.5^{\mathrm{e}, \mathrm{f}}$ & $20.9 \pm 0.2^{\mathrm{e}, \mathrm{f}}$ & $55.5 \pm 4.5^{\mathrm{g}, \mathrm{h}}$ & $74.1 \pm 6.2^{\mathrm{e}, \mathrm{f}}$ & $76.8 \pm 3.6^{\mathrm{e}, \mathrm{f}}$ \\
\hline POS7 & $42.5 \pm 2.8^{\mathrm{a}}$ & $41.2 \pm 1.5^{\mathrm{a}}$ & $42.7 \pm 1.1^{\mathrm{a}}$ & $143.6 \pm 8.7^{\mathrm{a}}$ & $121.0 \pm 5.4^{b}$ & $102.1 \pm 3.9^{c}$ \\
\hline PROF1 & $26.1 \pm 0.6^{d}$ & $15.0 \pm 9.2^{\mathrm{g}}$ & $29.0 \pm 1.9^{\mathrm{c}, \mathrm{d}}$ & $68.9 \pm 9.5^{\mathrm{f,g}}$ & $75.2 \pm 9.7^{\mathrm{d}, \mathrm{e}, \mathrm{f}}$ & $100.2 \pm 13.4^{c}$ \\
\hline PROF4 & $24.2 \pm 0.6^{\mathrm{d}, \mathrm{e}}$ & $25.0 \pm 1.3^{\mathrm{c}, \mathrm{d}}$ & $20.2 \pm 0.9^{\mathrm{e}, \mathrm{f}}$ & $48.7 \pm 1.3^{\mathrm{h}, \mathrm{i}}$ & $74.9 \pm 2.3^{\mathrm{e}, \mathrm{f}}$ & $83.2 \pm 7.3^{\mathrm{d}, \mathrm{e}}$ \\
\hline PROF6 & $21.9 \pm 2.0^{\mathrm{e}, \mathrm{f}}$ & $28.6 \pm 1.5^{\mathrm{c}, \mathrm{d}}$ & $25.2 \pm 2.1^{\mathrm{c}, \mathrm{d}}$ & $65.3 \pm 5.9^{f, g}$ & $95.1 \pm 9.1^{\mathrm{c}}$ & $98.7 \pm 8.9^{c}$ \\
\hline PROF8 & $25.3 \pm 1.7^{\mathrm{c}, \mathrm{d}}$ & $26.8 \pm 1.7^{\mathrm{c}, \mathrm{d}}$ & $22.7 \pm 4.6^{\mathrm{d}, \mathrm{e}}$ & $77.2 \pm 8.5^{\mathrm{d}, \mathrm{e}, \mathrm{f}}$ & $96.4 \pm 15.6^{\mathrm{c}}$ & $88.2 \pm 13.2^{\mathrm{c}, \mathrm{d}, \mathrm{e}}$ \\
\hline POS6 & $27.3 \pm 3.1^{\mathrm{c}, \mathrm{d}}$ & $24.4 \pm 0.7^{\mathrm{d}, \mathrm{e}}$ & $32.6 \pm 1.2^{\mathrm{c}}$ & $61.3 \pm 4.3^{\mathrm{f}, \mathrm{g}}$ & $64.2 \pm 6.5^{\mathrm{f}, \mathrm{g}}$ & $82.9 \pm 2.0^{\mathrm{d}, \mathrm{e}}$ \\
\hline POS11 & $28.7 \pm 0.7^{\mathrm{c}, \mathrm{d}}$ & $28.4 \pm 0.4^{\mathrm{c}, \mathrm{d}}$ & $27.8 \pm 7.8^{\mathrm{c}, \mathrm{d}}$ & $51.8 \pm 10.7^{\mathrm{g}, \mathrm{h}, \mathrm{i}}$ & $49.3 \pm 7.4^{\mathrm{g}, \mathrm{h}, \mathrm{i}}$ & $66.1 \pm 9.7^{\mathrm{f}, \mathrm{g}, \mathrm{h}}$ \\
\hline TRICHO4 & $25.0 \pm 0.7^{\mathrm{c}, \mathrm{d}, \mathrm{e}}$ & $34.8 \pm 3.1^{\mathrm{b}, \mathrm{c}}$ & $30.9 \pm 3.2^{\mathrm{c}}$ & $51.7 \pm 4.9^{\mathrm{g}, \mathrm{h}, \mathrm{i}}$ & $93.0 \pm 4.9^{\mathrm{c}, \mathrm{d}}$ & $79.9 \pm 7.8^{\mathrm{d}, \mathrm{e}}$ \\
\hline POS8 & $23.1 \pm 0.2^{\mathrm{d}, \mathrm{e}}$ & $28.7 \pm 0.4^{\mathrm{c}, \mathrm{d}}$ & $24.8 \pm 1.2^{\mathrm{d}, \mathrm{e}}$ & $69.2 \pm 0.6^{\mathrm{f}, \mathrm{g}}$ & $66.9 \pm 11.2^{f, g}$ & $64.3 \pm 6.1^{\mathrm{f}, \mathrm{g}}$ \\
\hline POS10 & $25.4 \pm 2.3^{\mathrm{c}, \mathrm{d}}$ & $22.3 \pm 4.6^{\mathrm{c}, \mathrm{d}, \mathrm{e}}$ & $25.5 \pm 2.6^{\mathrm{c}, \mathrm{d}}$ & $47.1 \pm 5.5^{\mathrm{h}, \mathrm{i}}$ & $65.7 \pm 9.2^{\mathrm{f}, \mathrm{g}}$ & $58.9 \pm 9.2^{\mathrm{g}, \mathrm{h}}$ \\
\hline NAN11 & $23.2 \pm 1.8^{\mathrm{d}, \mathrm{e}}$ & $26.1 \pm 0.8^{\mathrm{c}, \mathrm{d}}$ & $29.9 \pm 1.0^{\mathrm{c}, \mathrm{d}}$ & $43.3 \pm 2.7^{\mathrm{h}, \mathrm{i}}$ & $59.5 \pm 9.7^{\mathrm{g}, \mathrm{h}}$ & $74.8 \pm 0.2^{\mathrm{e}, \mathrm{f}}$ \\
\hline PROF2 & $21.3 \pm 0.3^{\mathrm{e}, \mathrm{f}}$ & $21.5 \pm 0.7^{\mathrm{e}, \mathrm{f}}$ & $22.7 \pm 1.7^{\mathrm{e}, \mathrm{f}}$ & $47.9 \pm 2.0^{\mathrm{h}, \mathrm{i}}$ & $59.8 \pm 8.7^{\mathrm{g}, \mathrm{h}}$ & $49.4 \pm 11.7^{\mathrm{g}, \mathrm{h}, \mathrm{i}}$ \\
\hline NAN9 & $18.1 \pm 2.1^{\mathrm{g}}$ & $17.1 \pm 2.4^{\mathrm{g}}$ & $19.3 \pm 1.3^{\mathrm{g}}$ & $18.3 \pm 0.9^{\mathrm{j}}$ & $17.9 \pm 0.4^{\mathrm{j}}$ & $17.5 \pm 0.1^{\mathrm{j}}$ \\
\hline
\end{tabular}




\begin{tabular}{|c|c|c|c|c|c|c|}
\hline \multicolumn{7}{|c|}{ Quantitative assays (U/L) $\left(\right.$ mean \pm SD) $^{1}$} \\
\hline \multirow{2}{*}{$\begin{array}{l}\text { Fungal } \\
\text { isolate }\end{array}$} & \multicolumn{3}{|c|}{ CBHs activity } & \multicolumn{3}{|c|}{ BGLs activity } \\
\hline & Day 3 & Day 4 & Day5 & Day 3 & Day 4 & Day 5 \\
\hline PROF5 & $35.1 \pm 0.2^{\mathrm{h}}$ & $54,1 \pm 4.9^{\mathrm{e}, \mathrm{f}}$ & $65.5 \pm 6.3^{\mathrm{d}, \mathrm{e}}$ & $1.5 \pm 0.2^{\mathrm{d}}$ & $2.3 \pm 0.4^{\mathrm{c}}$ & $2.4 \pm 0.7^{\mathrm{c}}$ \\
\hline PROF7 & $100.9 \pm 0.3^{\mathrm{a}}$ & $101.9 \pm 0.4^{\mathrm{a}}$ & $55.4 \pm 1.3^{\mathrm{e}, \mathrm{f}}$ & $0.4 \pm 0.1^{\mathrm{f}}$ & $0.4 \pm 0.1^{\mathrm{f}}$ & $0.6 \pm 0.3^{\mathrm{e}, \mathrm{f}}$ \\
\hline NAN13 & $100.9 \pm 8.8^{\mathrm{a}, \mathrm{b}}$ & $79.5 \pm 1.2^{\mathrm{c}, \mathrm{d}}$ & $75.6 \pm 3.2^{\mathrm{c}, \mathrm{d}}$ & $1.2 \pm 0.2^{\mathrm{d}, \mathrm{e}}$ & $1.4 \pm 0.3^{\mathrm{d}}$ & $1.6 \pm 0.2^{\mathrm{d}}$ \\
\hline TEYU14 & $65.5 \pm 9.2^{\mathrm{d}, \mathrm{e}}$ & $56.1 \pm 5.3^{\mathrm{e}, \mathrm{f}}$ & $76.3 \pm 1.9^{\mathrm{c}, \mathrm{d}}$ & $1.9 \pm 0.6^{\mathrm{c}, \mathrm{d}}$ & $3.1 \pm 0.1^{\mathrm{c}}$ & $3.1 \pm 0.1^{\mathrm{c}}$ \\
\hline POS3 & $71.9 \pm 1.6^{\mathrm{c}, \mathrm{d}}$ & $36.4 \pm 1.2^{\mathrm{h}}$ & $40.2 \pm 1.3^{\mathrm{g}, \mathrm{h}}$ & $0.2 \pm 0.1^{\mathrm{f}}$ & $0.3 \pm 0.1^{\mathrm{f}}$ & $0.4 \pm 0.1^{\mathrm{f}}$ \\
\hline POS7 & $35.1 \pm 0.2^{\mathrm{h}}$ & $88.3 \pm 12.3^{b, c}$ & $102.3 \pm 2.5^{\mathrm{a}}$ & $7.7 \pm 0.2^{b}$ & $7.2 \pm 0.2^{b}$ & $9.2 \pm 0.1^{\mathrm{a}}$ \\
\hline PROF1 & $35.1 \pm 0.2^{\mathrm{h}}$ & $42.7 \pm 7.6^{\mathrm{g}, \mathrm{h}}$ & $56.1 \pm 5.6^{\mathrm{e}, \mathrm{f}}$ & $0.5 \pm 0.1^{\mathrm{e}, \mathrm{f}}$ & $0.6 \pm 0.1^{\mathrm{e}, \mathrm{f}}$ & $1.1 \pm 0.1^{\mathrm{e}}$ \\
\hline PROF4 & $52.9 \pm 6.7^{\mathrm{e}, \mathrm{f}}$ & $104.3 \pm 1.9^{a}$ & $65.1 \pm 8.7^{\mathrm{d}, \mathrm{e}}$ & $1.1 \pm 0.1^{\mathrm{e}}$ & $1.5 \pm 0.2^{\mathrm{d}}$ & $1.7 \pm 0.2^{\mathrm{d}}$ \\
\hline PROF6 & $43.9 \pm 8.8^{\mathrm{e}, \mathrm{f}, \mathrm{g}}$ & $63.0 \pm 5.1^{\mathrm{d}, \mathrm{e}}$ & $82.7 \pm 0.9^{c}$ & $0.3 \pm 0.1^{\mathrm{f}}$ & $0.4 \pm 0.1^{\mathrm{f}}$ & $1.2 \pm 0.5^{\mathrm{d}, \mathrm{e}}$ \\
\hline PROF8 & $65.5 \pm 9.8^{\mathrm{d}, \mathrm{e}}$ & $73.2 \pm 7.9^{\mathrm{c}, \mathrm{d}, \mathrm{e}}$ & $68.2 \pm 6.9^{\mathrm{d}, \mathrm{e}}$ & $0.9 \pm 0.2^{\mathrm{e}}$ & $1.3 \pm 0.3^{\mathrm{d}, \mathrm{e}}$ & $2.3 \pm 0.2^{\mathrm{c}}$ \\
\hline POS6 & $69.4 \pm 1.2^{\mathrm{d}, \mathrm{e}}$ & $89.0 \pm 13.5^{\mathrm{b}, \mathrm{c}}$ & $73.1 \pm 15.7^{\mathrm{c}, \mathrm{d}}$ & $0.1 \pm 0.1^{\mathrm{f}}$ & $0.1 \pm 0.1^{\mathrm{f}}$ & $0.2 \pm 0.1^{\mathrm{f}}$ \\
\hline POS11 & $50.3 \pm 2.4^{\mathrm{e}, \mathrm{f}}$ & $40.7 \pm 2.6^{\mathrm{g}, \mathrm{h}}$ & $47.5 \pm 3.7^{\mathrm{g}, \mathrm{h}}$ & $0.4 \pm 0.2^{\mathrm{e}, \mathrm{f}}$ & $0.9 \pm 0.2^{\mathrm{e}}$ & $1.4 \pm 0.1^{\mathrm{d}}$ \\
\hline TRICHO4 & $90.3 \pm 13.4^{\mathrm{a}, \mathrm{b}, \mathrm{c}}$ & $64.3 \pm 0.2^{\mathrm{d}, \mathrm{e}}$ & $35.1 \pm 0.1^{\mathrm{h}}$ & $0.6 \pm 0.2^{\mathrm{e}, \mathrm{f}}$ & $0.7 \pm 0.1^{\mathrm{e}}$ & $1.5 \pm 0.1^{\mathrm{d}}$ \\
\hline POS8 & $49.1 \pm 11.2^{\mathrm{f}, \mathrm{g}, \mathrm{h}}$ & $45.9 \pm 9.5^{\mathrm{f,g,h}}$ & $45.9 \pm 9.3^{\mathrm{f}, \mathrm{g}, \mathrm{h}}$ & $0.8 \pm 0.4^{\mathrm{e}, \mathrm{f}}$ & $1.9 \pm 0.3^{\mathrm{d}}$ & $2.3 \pm 0.4^{\mathrm{c}}$ \\
\hline POS10 & $72.4 \pm 9.5^{\mathrm{c}, \mathrm{d}}$ & $41.4 \pm 6.3^{\mathrm{g}, \mathrm{h}}$ & $70.6 \pm 5.7^{\mathrm{c}, \mathrm{d}}$ & $0.3 \pm 0.1^{\mathrm{f}}$ & $0.3 \pm 0.2^{\mathrm{f}}$ & $0.2 \pm 0.1^{\mathrm{f}}$ \\
\hline NAN11 & $52.2 \pm 15.2^{\mathrm{e}, \mathrm{f}}$ & $58.7 \pm 7.8^{\mathrm{e}, \mathrm{f}}$ & $41.5 \pm 0.5^{\mathrm{h}}$ & $0.9 \pm 0.1^{\mathrm{e}}$ & $1.2 \pm 0.1^{\mathrm{e}}$ & $1.8 \pm 0.3^{\mathrm{d}}$ \\
\hline PROF2 & $35.1 \pm 0.2^{\mathrm{h}}$ & $35.1 \pm 0.3^{\mathrm{h}}$ & $65.2 \pm 7.6^{\mathrm{d}, \mathrm{e}}$ & $0.7 \pm 0.1^{\mathrm{e}}$ & $0.8 \pm 0.1^{\mathrm{e}}$ & $1.1 \pm 0.2^{\mathrm{e}}$ \\
\hline NAN9 & $15.1 \pm 0.2^{\mathrm{j}}$ & $16.2 \pm 0.3^{j}$ & $25.7 \pm 2.7^{\mathrm{i}}$ & $0.0^{\mathrm{g}}$ & $0.05 \pm 0.02^{\mathrm{g}}$ & $0.05 \pm 0.01^{\mathrm{g}}$ \\
\hline
\end{tabular}

Legend: Data are the mean of three replicates; ${ }^{1}$ Letters indicate significant differences between fungi grown on each culture medium (LSD test, $\mathrm{p}<0.05)$.

\section{Morphological identification}

After the incubation period, the colonies of the Trichoderma POS7 isolate showed rapid growth in both culture media. In MEA the mean growth rate for day was $2.19 \mathrm{~cm}$ (SD 0.12), and in PDA was $2.37 \mathrm{~cm}$ (SD 0.16). Regarding the color of the colonies it was observed a progressive change in their coloration, from a white and cottony color colony to a bright light green and light yellow color of velvety texture colony in both culture media. These features were more conspicuous in MEA culture medium (Fig 2).

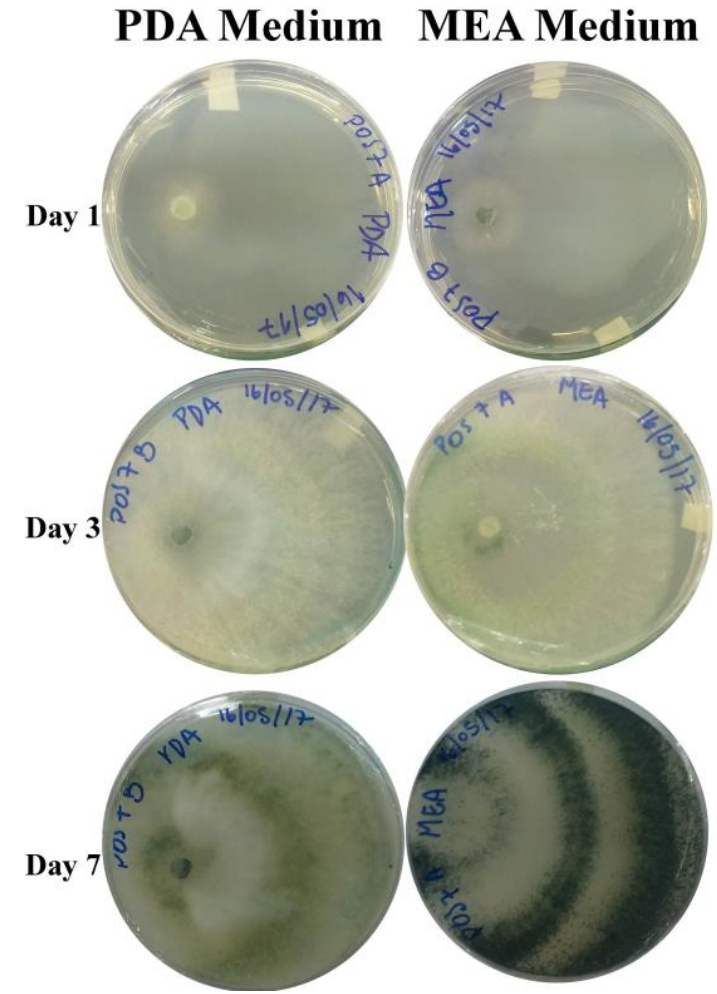

Figure 2 Macroscopic colonial features of the Trichoderma POS7 isolate grown in PDA and MEA culture media

Microscopically, this isolate showed a more or less a regular pattern of indefinite branching, and a typical of Trichoderma terminal branches penicillated. Also, Trichoderma POS7 isolate showed regularly aculeate phialides on a relatively well-defined stipe. The conidiophore branching was regularly verticillate Branches were relatively narrow and flexuous. It was observed that the phialides were disposed in regular verticils. The phialide shape lageniform to nearly cylindrical and elongated. Like in most Trichoderma species, the terminal phialides were elongated and narrowed. They showed a length of $7.40 \mu \mathrm{m}$ (SD 0.73 ) after $72 \mathrm{~h}$ of incubation; the width of the observed base region was $1.46 \mu \mathrm{m}$ (SD 0.33); and, the width of the apex region of the phialides presented a size of $0.93 \mu \mathrm{m}$ (SD 0.24). Conidial shape varied from globose to ellipsoidal. The length of the conidia at $72 \mathrm{~h}$ of incubation was $2.77 \mu \mathrm{m}$ (SD 0.44) with a width of 1.67 $\mu \mathrm{m}$ (SD 0.31) (Fig 3).

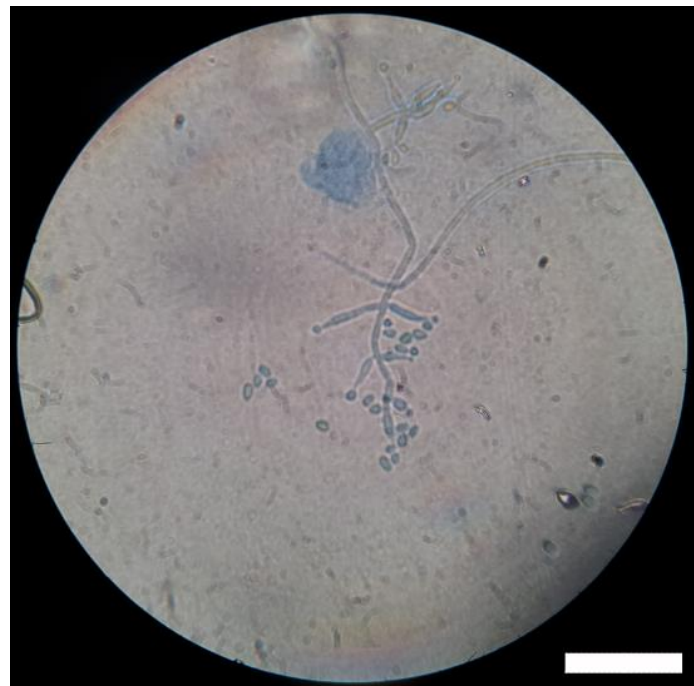

Figure 3 Microscopic features of the Trichoderma POS7 isolate. Microculture technique and lactophenol cotton blue staining with adhesive tape method were used to facilitate the observation. $\mathrm{Bar}=20 \mu \mathrm{m}$.

\section{Molecular identification and phylogenetic analysis}

Genomic DNA of Trichoderma POS7 isolate had a 260 / 280 absorbance ratio of 1.75. The ITS1-5.8S-ITS2 nucleotide sequence obtained had a length of $534 \mathrm{bp}$ after contig construction and was deposited in GenBank-NCBI under accession number KT030879.

The comparison and analysis of Trichoderma POS7 sequence with deposited sequences in genetic databases allowed us to define this sequence as belonging to Trichoderma koningiopsis species with 99\% of identity with KC884811 and KC884814 accession numbers from Fungal barcoding and NCBI databases, respectively. TrichOKEY database, a specific and curated database for molecular identification of Trichoderma and Hypocrea species, also allowed us to define the Trichoderma POS7 sequence as belonging to T. koningiopsis species.

The trees obtained by the NJ, ML and MP methods showed a similar topography indicating that the datasets could be combined. The ITS1-5.8S-ITS2 phylogenetic trees revealed that the isolate under study belongs to the same monophyletic clade of T. koningiopsis species (85\% bootstrap) (Fig 4).

The phylogenetic analyses revealed close positioning of $T$. koningiopsis with $T$. viride, $T$. viridescens and $T$. petersenii in a closely related group, in concordance with the actual taxonomic classification of Viride clade in Trichoderma section. T. asperellum and T. hamatum revealed close positioning in the Hamatum clade in the same Trichoderma section. $T$. longibrachiatum, $T$. reesei, and $T$. citrinoviride showed close positioning in the Longibrachiatum clade in Longibrachiatum section, close to the Trichoderma section. Moreover, the Hypocreamun section included the Ceramica, Megalocitrina and Chlorospora clades and the Pachybasidium section included the Virens and Harzianum clades, these two sections revealed a closely related group. Finally, $T$. brevicompactum 
species, belonging to the Lutea clade (Lone Lineages Section) showed high genetic distance with the other species of Trichoderma (Fig 4).

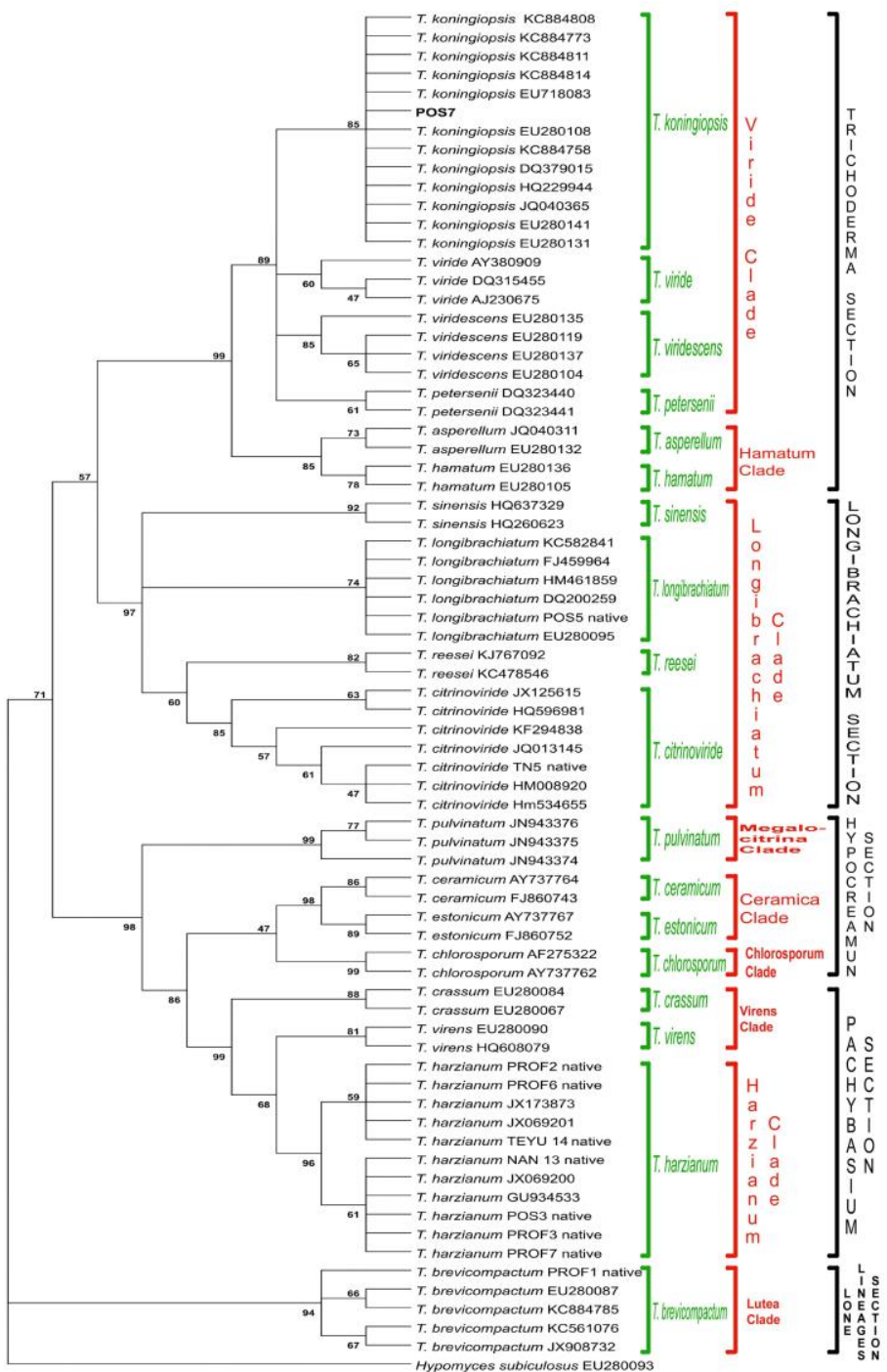

Figure 4 Phylogenetic tree based on MP method of the ITS1-5.8S-ITS2 sequence of Trichoderma POS7 isolate and the obtained sequences of GenBank and Fungal barcoding databases.

\section{DISCUSSION}

The fungal enzymatic degradation of cellulose has been suggested as a feasible alternative to produce bioethanol (Akinyele et al., 2014; Ma and Ruan, 2015) Therefore, different studies on cellulase produced by fungi, particularly by Trichoderma strains were developed and many signs of progress have been made (Mandels and Reese, 1957; Doolotkeldieva and Bobusheva, 2011; Druzhinina et al., 2011). In spite of some present successes, the task of finding new highly active cellulase or efficient producers of cellulase remains topical (Zhou $\boldsymbol{e t}$ al., 2008; Zhang et al., 2014)

The province of Misiones (Argentina), an ecoregion of the Atlantic Forest, is one of the most valuable sites of wet subtropical ecosystems on biodiversity. The biota of the Atlantic Forest is extremely diverse and the assessment of the current state of this region's biodiversity is still poorly known (Bich et al., 2015; Fernandez et al., 2017). For this reason, in this study twenty-eight Trichoderma isolates were evaluated to reveal new players in cellulose degradation.

\section{Biochemical analyses}

Various authors reported that the Mandels' medium is a complex nitrogenous source that induces cellulase secretion in microorganisms (Mandels and Reese, 1957; Doolotkeldieva and Bobusheva, 2011; de Eugenio et al., 2017). CMC substrate is a water-soluble cellulose product and is a suggested substrate for detection of cellulase secretion because it is degraded easily by microorganisms (Mandels and Reese, 1957; Mandels and Andreotti, 1976; Sazci et al., 1986; Doolotkeldieva and Bobusheva, 2011; Ray et al., 2013; Akinyele et al., 2014; de Eugenio et al., 2017).

The Congo red dye was used as an indicator for $\beta$-1,4-glycosidic bonds degradation in an agar medium. This simple diffusion technique provides a rapid and sensitive screening test for cellulolytic microorganisms (Sazci et al., 1986; Doolotkeldieva and Bobusheva, 2011; Florencio et al., 2012).

In this study, all isolates of Trichoderma were classified into five categories based on the qualitative enzymatic activity. This method, conducted in plates, resulted rapid, simple, and well adapted for the screening high amount of samples of the same genus. Likewise, Hankin and Anagnostakis (1975), Doolotkeldieva and Bobusheva (2011) and Florencio et al. (2012) reported that the extracellular enzymes can be produced in solid and liquid media, nonetheless the use of solid media enables rapid assays and can be useful for the isolation and detection of cellulase-producing organisms from natural materials.

The most widely accepted mechanism of enzymatic hydrolysis proposes that synergistic cooperation of EGs, CBHs and BGLs is a prerequisite for the efficient degradation of cellulose (Sun and Cheng, 2002; Ouyang et al., 2006; Zhang et al., 2014). Thus, when there is a lack of synergism, an incomplete hydrolysis can occur due to an incomplete cellulase system or an insufficient enzyme loading (Martinez-Anaya et al., 2008). In this study, the enzymatic synergism was evidenced when the maximum EGs activity was increased at early days of incubation while the maximum $\mathrm{CBHs}$ activity was increased at the end of the incubation period. Hence, the action of CBHs occurred after the action of EGs. The conventional mechanistic interpretation of the synergism between randomly acting EGs and chain end-specific processive $\mathrm{CBHs}$ is that the new chain end on cellulose surface generated by the EGs action serves as starting points for the $\mathrm{CBHs}$ action. Considering the crystalline nature of a substrate like cellulose, the number of reducing chain ends available for $\mathrm{CBHs}$ is expected to be low. The conventional explanation of EGs-CBHs synergism assumes that the chain end availability is rate-limiting for $\mathrm{CBH}$ so that generation of new chain end by EGs will increase the population of productive CBHs cellulose complexes (Jalak $\boldsymbol{e t}$ al., 2012).

In many isolates (NAN13 - PROF4 - PROF7) the maximum CBHs activity increase was observed before the maximum EGs activity $(\mathrm{p}<0.05)$. This could be due to the number of reducing chain ends available in the substrate (MartinezAnaya et al., 2008; Jalak et al., 2012).

The BGLs hydrolyze cellobiose and cello-oligosaccharides to form glucose, so their effects must take place after the EGs and CBHs action (Zhang et al., 2014) In this study, it was observed that the maximum BGLs activity occurred after the maximum EGs and CBHs activities in all isolates. These results evidence the synergism among cellulase complex enzymes.

The correlation between qualitative screening with Congo red technique and quantitative screening with dinitrosalicylic acid reagent method was first reported by Sazci $\boldsymbol{e t}$ al. (1986) and Florencio et al. (2012). In this study, the congruence between both methods was verified; the clear zones around fungal colonies in solid Mandels' medium with CMC substrate had congruence with the FPA, EGs and CBHs activities. Therefore, the qualitative assays can be used in a sensitive cheap, reproducible and rapid way for screening a large number of cellulaseproducing fungi (Sazci et al., 1986; Doolotkeldieva and Bobusheva, 2011; Druzhinina et al., 2011).

\section{Morphological and molecular identification and phylogenetic analyses}

Trichoderma strains usually can be identified to genus level by a distinctive morphology that includes rapid growth, bright green or white conidial pigments, and a repetitively branched conidiophore (Kubicek and Harman, 2002). The morphological characters used to identify the T. koningiopsis POS7 isolate were in agreement with the morphological characters typical of this species (Samuels, 2006).

The advent of molecular tools for investigations in fungal taxonomy prompted the reassessment of the morphology-based taxonomy in Trichoderma species (Druzhinina and Kubicek, 2005). Molecular methods do not replace morphological characterization; conversely, they complement morphological methods. New DNA sequence analysis has clarified the taxonomy of many Trichoderma species, and even several new species have been described with multigenic phylogenies (Samuels, 2006; Druzhinina et al., 2012). In this study, we decided to use and contrast the information provided by a specific database for the genus Trichoderma (TrichOKEY), a primary database (NCBI) and a curated database (Fungal barcoding). These identification analyses generated a greater approach to taxonomic identification of the isolate under study.

For identification of Trichoderma strains, TrichOKEY and TrichoBLAST (www.isth.info) are suggested as appropriate tools freely available online (Hassan et al., 2015). The GenBank database contains many sequences of Trichoderma isolates which had been incorrectly identified and several of them may be redundant (i.e. synonyms of other described species) or not correctly placed in the genus. Hence, to make a more accurate identification of the Trichoderma POS7 sequence, it was decided to use only duly published sequences from Genbank and Fungal barcoding databases. The sequences indexed in different databases which alignments showed high score percent identity and low E-value were selected to use in the construction of the nucleotide sequence trees.

In this study, the Trichoderma POS7 sequence showed a close position with other T. koningiopsis deposited sequences. The generated trees showed high bootstrap values of $85 \%$ for $T$. koningiopsis clade. Several authors reported that values of 
$70 \%$ or higher are expected to indicate reliable groupings (Baldauf, 2003) Moreover, the phylogenetic analyses revealed close positioning of the $T$. koningiopsis clade with $T$. viride, $T$. viridescens and $T$. petersenii clades in a closely related group, in concordance with the current taxonomic classification of Trichoderma genus (Druzhinina et al., 2012; Gupta et al., 2014).

\section{CONCLUSION}

The cellulase secretory capacity of twenty-eight native fungi of Trichoderma genus was evaluated with the aim to explore new fungal isolates with high cellulase secretory capacity in Argentina. The morphological and molecular identification allowed us to classify the isolate that showed the highest cellulase activity as $T$. koningiopsis POS7. This isolate showed the highest enzymatic activity and was selected for further studies. Our results provide new information and reveal new microorganism in the hydrolysis of cellulose material. $T$. koningiopsis POS7 isolate can be used in further studies to optimize its cellulase secretion, leading to a better use and application enzimatic secretion like in lignocellulose saccharification for bioethanol production.

Acknowledgments: NSA, GAB and MDR are postgraduate CONICET fellowship holders, MLC is CONICET assistant researcher and PDZ is CONICET independent researcher.

\section{REFERENCES}

ADRIO, J.L., DEMAIN, A.L. 2014. Microbial Enzymes: tools for biotechnology processes. Biomolecules Journal. 4(1), 117-139. https://doi.org/10.3390/biom4010117

AKINYELE, J.B., FALADE, O.E., OLANIYI, O.O. 2014. Screening and optimization of culture conditions for cellulase production by Aspergillus niger nspr012 in submerged fermentation. Journal of Microbiology, Biotechnology and Food Sciences. 4(3), 189-193. http://dx.doi.org/10.15414/jmbfs.2014-15.4.3.189 193

AMIN, S.B., RAHMAN, S. 2019. Bioenergy: The Hope that Is After Gas. In Energy Resources in Bangladesh, Springer, 63-66. https://doi.org/10.1007/978-3030-02919-7_12

BAILEY, M.J. 1981. The effect of $\beta$-glucosidase on some assays for cellulolytic enzymes. Biotechnological Letters. 3, 695-700. https://doi.org/10.1007/BF00134846

BALDAUF, S.L. 2003. Phylogeny for the faint of heart: a tutorial. Review Trends in Genetics. 19(6), 345-351. https://doi.org/10.1016/S0168-9525(03)00112-4 BANDIKARI, R., MANNEPULA, S., POLUDASU, R., REDDY OBULAM, V 2015. Supplementation of fruit processing waste for endoxylanase production by Trichoderma koeningi isolate and its optimization using central composite design: application of produced endoxylanase in mango juice clarification Journal of Microbiology, Biotechnology and Food Sciences. 5(2), 162-166. http://dx.doi.org/10.15414/jmbfs.2015.5.2.162-166

BICH, G.A., CASTRILLO, M.L., SILVA, M.R., DÍAZ, G.V., VILLALBA, L.L., ZAPATA, P.D., MEDVEDEFF, M.G. 2015. Hongos entomopatógenos en la provincia de Misiones: Revisión. Recyt. 23(5), 54-58.

BICH, G.A., CASTRILlO, M.L., VILlALBA, L.L., ZAPATA, P.D. 2017. Isolation of the symbiotic fungus of Acromyrmex pubescens and phylogeny of Leucoagaricus gongylophorus from leaf-cutting ants. Saudi Journal of Biological Science. 24(4), 851-856. https://doi.org/10.1016/j.sjbs.2016.05.010 CASTRILlO, M.L., FONSECA, M.I., BICH, G.A., JERKE, G., HORIANSKI, M.A., ZAPATA, P.D. 2012.Taxonomy and phylogenetic analysis of Aspergillus section nigri isolated from yerba mate in Misiones (Argentina). Journal of Basic and Applied Genetics. 23(2), 19-27.

CASTRILLO ML, BICH GA, ZAPATA PD, VILLALBA LL. 2016. Biocontrol of Leucoagaricus gongylophorus of leaf-cutting ants with the mycoparasitic agent Trichoderma koningiopsis. Mycosphere. 7, 810-819.

DE EUGENIO, L.I., MÉNDEZ-LÍTER, J.A., NIETO-DOMÍNGUEZ, M. ALONSO, L., GIL-MUÑOZ, J., BARRIUSO, J., PRIETO, A., MARTÍNEZ, M.J. 2017. Differential $\beta$-glucosidase expression as a function of carbon source availability in Talaromyces amestolkiae: a genomic and proteomic approach Biotechnology for Biofuels. 10, 161. https://doi.org/10.1186/s13068-017-0844-7 DOOLOTKELDIEVA, T., BOBUSHEVA, S. 2011. Screening of Wild-Type Fungal Isolates for Cellulolytic Activity. Microbial Insights. 4, 1-10. DOS SANTOS CASTRO, L., RAMOS PEDERSOLI, W., CAMPOS ANTONIÊTO, A., STECCA STEINDORFF, A., SILVA-ROCHA, R., MARTINEZ-ROSSI, N., ROSSI, A., ANDREW BROWN, N., GOLDMAN, G., FAÇA, V., PERSINOTI, R., SILVA, R. 2014. Comparative metabolism of cellulose, sophorose and glucose in Trichoderma reesei using high-throughput genomic and proteomic analyses. Biotechnology for Biofuels. 7, 1-41. https://doi.org/10.1186/1754-6834-7-41

DRUZHININA, I.S., KUBICEK, C.P. 2005.Species concepts and biodiversity in Trichoderma and Hypocrea: from aggregate species to species clusters? Journal of Zheijang University SCIENCE. 6(2), 100-112. https://doi.org/10.1631/jzus.2005.B0100
DRUZHININA, I.S., SEIDL-SEIBOTH, V., HERRERA-ESTRELLA, A., HORWITZ, B., KENERLEY, C., MONTE, E., MUKHERJEE, P., ZEILINGER, S., GRIGORIEV, I., KUBICEK, C.P. 2011. Trichoderma: the genomics of $\begin{array}{llll}\text { opportunistic success. Nature Review. } & 9(12), & 749-759\end{array}$ https://doi.org/10.1038/nrmicro2637

DRUZHININA, I.S., KOMON-ZELAZOWSKA, M., ISMAIEL, A., JAKLITSCH, W., MULLAW, T., SAMUELS, G., KUBICEK, C.P. 2012. Molecular phylogeny and species delimitation in the section Longibrachiatum of Trichoderma. Fungal Genetics and Biology. 49(5), 358-368. https://doi.org/10.1016/j.fgb.2012.02.004

FERNANDEZ, R.D., BULACIO, N., ALVAREZ, A., PAJOT, H., ARAGON, R. 2017. Fungal decomposers of leaf litter from an invaded and native mountain forest of NW Argentina. Antonie Van Leeuwenhoek. 110(9), 1207-1218. https://doi.org/ 10.1007/s10482-017-0893-8

FLORENCIO, C., COURI, S., SANCHEZ FARINAS, C. 2012. Correlation between agar plate screening and solid-state fermentation for the prediction of cellulase production by Trichoderma strains. Enzyme Research. 2012, 1-7. http://dx.doi.org/10.1155/2012/793708

GHOSE, T. 1987. Measurement of cellulase activities. Pure and Applied Chemistry. 59(2), 257-268.

GUPTA, V.K., SCHMOLL, M., HERRERA-ESTRELLA, A., UPADHYAY, R.S., DRUZHININA, I.S., TUOHY, M.G. 2014. Biotechnology and Biology of Trichoderma. Elseiver, Amsterdam, The Netherlands. 650 p. ISBN: 9780444595942

HANKIN, L., ANAGNOSTAKIS, S. 1975. The use of solid media for detection of enzyme production by fungi. Mycology. 67(3), 597-607. https://doi.org/10.2307/3758395

HASSAN, G., EL-FEKY, Z., HEMADA, N., SAYED, M. 2015. Isolation and molecular characterization of egyptian Trichoderma and assessment of their antagonistic potential against Rhizoctonia solani. Journal of Microbiology, $\begin{array}{llll}\text { Biotechnology and Food Sciences. 4(6), 496-502. } & \end{array}$ http://dx.doi.org/10.15414/jmbfs.2015.4.6.495-502

HIBBETT, D., ABARENKOV, K., KÕLJALG, U., ÖPIK, M., CHAI, B., COLE, J., WANG Q., CROUS P., ROBERT V., HELGASON T., HERR, J. R., KIRK P., LUESCHOW S., O'DONELL K., NILSSON R.H., OONO R., SCHOCH C., SMYTH C., WALKER D., PORRAS-ALFARO A., TAYLOR J., GEISER D. M. (2017). Sequence-based classification and identification of Fungi. Mycologia, 108(6), 1049-1068.

JALAK, J., KURAŠHIN, M., TEUGJAS, H., VÄLJAMÄE, P. 2012. Endo-exo synergism in cellulose hydrolysis revisited. Journal of Biological Chemistry. 287 28802-28815. https://doi.org/10.1074/jbc.M112.381624

KAWAI, T., NAKAZAWA, H., IDA, N., OKADA, H., OGASAWARA, W., MORIKAWA, Y., KOBAYASHI, Y. 2013. A comprehensive analysis of the effects of the main component enzymes of cellulase derived from Trichoderma reesei on biomass saccharification. Journal of Industrial Microbiology and Biotechnology. 40(8), 805-810. https://doi.org/10.1007/s10295-013-1290-6

KUBICEK, C.P., HARMAN, G.E. 2002. Trichoderma \& Gliocladium. Volumen 1. Basic biology, taxonomy and genetics. Taylor \& Francis. London, 300 p. ISBN 9780748405725

LEAW, S.N., CHANG, H.C., SUN, H.F., BARTON, R., BOUCHARA, J.P., CHANG, T.C. 2006. Identification of medically important yeast species by sequence analysis of the internal transcribed spacer regions. Journal of Clinical Microbiology. 44(3), 693-699. https://doi.org/10.1128/JCM.44.3.693-699.2006 MA, K., RUAN, Z. 2015. Production of a lignocellulolytic enzyme system for simultaneous bio-delignification and saccharification of corn stover employing co-culture of fungi. Bioresource Technology. 175, 586-593. https://doi.org/ 10.1016/j.biortech.2014.10.161

MANDELS, M., REESE, E. 1957. Induction of cellulase in Trichoderma viride as influenced by carbon source and metals. Journal of Bacteriology. 73(2), 269278

MANDELS, M., ANDREOTTI, R.C. 1976. Measurement of saccharifying cellulase. Biotechnology and Bioenginering Symposium Journal. 6, 21-33.

MARTÍNEZ-ANAYA, C., BALCÁZAR-LÓPEZ, E., DANTÁN-GONZÁLEZ E., FOLCH-MALLOL, J. 2008. Celulasas fúngicas: aspectos biológicos y aplicaciones en la industria energética. Revista Latinoamericana de Microbiología. 50, 119-131.

MILLER, G.L. 1959. Use of Dinitrosalicylic Acid Reagent for Determination of Reducing Sugar. Analytical Chemistry. 31(3), 426-428. https://doi.org/10.1021/ac60147a030

NIGAM, P., SINGH, A. 2011. Production of liquid biofuels from renewable resources. Progress in Energy and Combustion Science. 37(1), 52-68 https://doi.org/10.1016/j.pecs.2010.01.003

OUYANG, J., YAN, M., KONG, D., XU, L. 2006. A complete protein pattern of cellulase and hemicellulase genes in the filamentous fungus Trichoderma reesei. Biotechnology Journal. 1(11), 1266-1274.

PATEL, A.K., RANI SINGHANIA, R., JUN SIM, S., PANDEY, A. 2019. Thermostable cellulases: review and perspectives. Bioresource Technology. https://doi.org/10.1016/i.biortech.2019.01.049

PERSOON, C. 1794. Disposita methodica fungorum. Römer's Neues Mag. Journal of Botany. 1, 81-128. 
PIONTELLI, E. 2015. Manual de microhongos filamentosos comunes. Chile. 462 p.

PRATS, G. 2007. Microbiología Clínica. Editorial Médica Panamericana, Buenos Aires, Argentina. 366 p. ISBN 847903971x

RATHNAN, R., JOHN, D., BALASARAVANAN, T. 2013. Isolation, screening, identification and optimized production of extracellular cellulase from Bacillus subtilis using cellulosic waste as carbon source. Journal of Microbiology, Biotechnology and Food Sciences. 2(6), 2383-2386.

RAY, R., DUTTA, W., SUR, D., KUNDU, A. 2013. Optimization of fermentation parameters for the production of extracellular endoglucanase, $\beta$-glucosidase and endoxylanase by a chromium resistant strain of Trichoderma pseudokoningii. Journal of Microbiology, Biotechnology and Food Sciences. 3(1), 54-58.

RIFAI, M. 1969. A revision of the genus Trichoderma. Commonw Mycol Inst Mycol Pap. 116, 1-56.

RODRIGUEZ M.D., ALONSO PAIVA I.M., CASTRILLO M.L., ZAPATA P.D., VILLALBA L.L. $2019 \mathrm{KH}_{2} \mathrm{PO}_{4}$ improves cellulase production of Irpex lacteus and Pycnoporus sanguineus. Journal of King Saud University - Science. https://doi.org/10.1016/j.jksus.2018.07.009

SADHU, S., SAHA, P., MAYILRAJ, S., MAITI, T. 2012. Characterization of a Bosea sp. strain sf5 (mtcc 10045) isolated from compost soil capable of producing cellulase. Journal of Microbiology, Biotechnology and Food Sciences. 2(2), 576-591.

SAMBROOK, J., FRITSCHI, E.F., MANIATIS, T. 1989. Molecular cloning: a laboratory manual. Cold Spring Harbor Laboratory Press, New York. 2028 p. ISBN:978-1-936113-42-2

SAMSON, R.A., EVANS, H.C., LATGÉ, J.P. 1988. Atlas of entomopathogenic fungi. Springer-Verlag Berlin Heidelberg. 198 p. ISBN 978-3-662-05890-9

SAMUELS, G. 2006. Trichoderma: Systematics, the sexual state and ecology. The nature and application of biocontrol microbes II: Trichoderma spp. Phytopathology Symptoms. 96(2), 195-206. https://doi.org/10.1094/PHYTO-96$\underline{0195}$

SAZCI, A., RADFORD, A., ERENLERR, K. 1986. Detection of cellulolytic fungi by using Congo red as an indicator: a comparative study with dinitrosalicyclic acid reagent method. Journal of Applied Bacteriology. 61(6), 559-562. https://doi.org/ 10.1111/j.1365-2672.1986.tb01729.x

SCHNEIDER, C.A., RASBAND, W.S., ELICEIRI, K.W. 2012. NIH Image to ImageJ: 25 years of image analysis. Nature. Methods. 9(7), 671-675.

SUN, Y., CHENG, J. 2002. Hydrolysis of lignocellulosic materials for ethanol production: a review. Bioresource Technology. 83(1), 1-11. https://doi.org/10.1016/S0960-8524(01)00212-7

TAMURA, K., STECHER, G., PETERSON, D., FILIPSKI, A., KUMAR, S

2013. MEGA6: Molecular Evolutionary Genetics Analysis Version 6.0. Molecular Biology and Evolution. 30(12), 2725-2729. https://doi.org/10.1093/molbev/mst197

THOMPSON, J.D., HIGGINGS, D.G., GIBSON, T.J. 1994. Clustal W improving the sensitivity of progressive multiple sequence alignment through sequence weighting, position-specific gap penalties and weight matrix choice Nucleic Acids Research. 22(22), 4673-4680.

WHITE, T., BURNS, T., LEE, S., TAYLOR, J. 1990. Amplification and direct sequencing of fungal ribosomal RNA genes for phylogenetics. In: Innis M.A., Gelfand D.H., Sninsky J.J., White T.J. PCR Protocols: A guide to methods and applications. Academy Press, San Diego, 315-322.

WOOD, T.M., BHAT, K.M. 1988. Methods for Measuring Cellulase Activities. Methods in Enzymology. 160, 87-112. https://doi.org/10.1016/00766879(88)60109-1

ZHANG, Z., LIU, J.L., LAN, J.Y., DUAN, C.J., MA, Q.S., FENG, J.X. 2014. Predominance of Trichoderma and Penicillium in cellulolytic aerobic filamentous fungi from subtropical and tropical forests in China, and their use in finding highly efficient b-glucosidase. Biotechnology for Biofuels. 7, 107-121. https://doi.org/10.1186/1754-6834-7-107

ZHOU, J., WANG, Y.H., CHU, J., ZHUANG, Y.P., ZHANG, S.L., YIN, P. 2008. Identification and purification of the main components of cellulase from a mutant strain of Trichoderma viride T 100-14. Bioresource Technology. 99(15), 6826-6833. https://doi.org/10.1016/j.biortech.2008.01.077 